\title{
Continuous in vitro rumen systems
}

\author{
By J. M. EwarT, Edinburgh School of Agriculture, West Mains Road, Edinburgh
} EH9 $37 G$

In vitro rumen experiments have been conducted for at least 40 years, and many research problems have been examined successfully by this approach. The simplest sub-division of in vitro rumen systems is into batch- and continuous-culture types. The batch-culture approach involves the provision of an initial supply only of substrate, which results in a culture in which the concentration of substrates is constantly falling while that of waste products rises. The continuous-culture type of in vitro rumen aims to replenish the substrates and remove waste products over an extended culture period. This is, of course, the situation in vivo and most in vitro systems have employed an intermittent addition of fresh substrate in order to simulate natural conditions as closely as possible. Before evaluating these and other systems it is profitable to consider the nature of the natural rumen as a microbial environment.

\section{Environmental factors in vivo}

The rumen is an anaerobic environment which imposes a strictly fermentative metabolism on the microflora. The products of fermentation are relatively reduced compounds, mainly volatile fatty acids (VFA) which the animal almost completely absorbs from the rumen (Gray, 1947; Kiddle, Marshall \& Phillipson, 195 I). Removal of the VFA is essential because their accumulation causes a diminution of the rate of fermentation (Starks, I956), presumably by end-product inhibition.

Physical factors are important, as the rumen is a stable microbial environment with temperature virtually constant, mixing at a steady rate, and with transport of materials in and out efficiently conducted by the host. Salivary flow is co-ordinated with food ingestion and this, combined with the fact that undissociated VFA are absorbed more quickly from the rumen than their anions (Masson \& Phillipson, I95 I Parthasarathy \& Phillipson, I953), ensures that $\mathrm{pH}$ is well controlled under most conditions.

Several workers, Hungate (1966), Hobson (1965), Postgate (1965) and Jannasch (I965) have recognised the analogy of the rumen with the continuous-culture model This implies that a 'realistic' in vitro rumen system must also be continuous.

Having considered the environmental factors encountered in vivo, a set of criteria for an in vitro system may be drawn up. Warner (1956) has established criteria of validity for in vitro rumens which are different from those suggested here as they 
were directed toward the microflora itself, not its environment. Thus it is desirable that an in vitro rumen should: (1) be anaerobic; (2) remove products of fermentation; (3) control temperature, $\mathrm{pH}$, mixing and substrate and culture flow; (4) be continuous, if the experimental period exceeds a few hours.

\section{The continuous in vitro rumen}

The theory of continuous culture, which was formalized by Monod (1950) and Novick \& Szilard (I950), is based on the fact that only one component in the substrate will be limiting microbial growth, and that culture density (the number of organisms present) is controlled by this component. The rate of microbial growth in the culture is dependent only on the rate of flow of substrate and may be controlled, within limits, by adjusting the rate of dilution. A full account of the theory has been given by Powell ( 1965 ).

For the theory to apply it is required that the substrate flow rate, and therefore the culture dilution rate, should remain constant and have a value within specified limits. The volume of the culture should also remain invariant. An apparatus enabling these characteristics to be achieved is a chemostat; Herbert, Phipps \& Tempest (1965) described the design and instrumentation of the chemostat.

Hungate (1966) has discussed the divergence of the rumen from the continuous culture model, particularly with respect to its non-linear kinetics, and concluded that the value of the continuous culture model lies not so much in its exact applicability as in providing a model for reference.

Many in vitro systems have recognised this divergence from the continuous model and have used periodic 'feeding'. Such systems are generally described as being continuous because the culture has been maintained over an extended period; at least several days. It might be advantageous if cultures were described as continuous only when they exist at a steady state; that is, having the same constitution at all times. Similarly the term 'fermentation patterns' is understood to describe the proportions of fermentation products such as acetic, propionic and butyric acids in the rumen (Hobson, 1972). The fact that these concentrations fluctuate in a periodic manner, in step with nutrient intake, is best illustrated by curve patterns following feeding. It is particularly in the sense that the rumen is 'cyclic' rather than 'steadystate' that the term continuous has a different meaning to the 'ruminologist' than to the microbiologist.

\section{In vitro rumen systems}

Table I details a number of in vitro systems which have been described. Louw, Williams \& Maynard (1949), Adler, Dye, Boggs \& Williams (1958), Harbers \& Tillman (1962) and Dawson, Ward \& Scott (1964) have also described in vitro systems.

Warner (1956) used an apparatus based on that of Louw et al. (1949) consisting of a semipermeable sac supported in dialysing solution. The sac contained $50 \mathrm{ml}$ of rumen liquor through which a stream of nitrogen with $5 \%$ carbon dioxide was passed. The $\mathrm{pH}$ of the culture was adjusted by the addition of buffer solution 'when 


\section{Table $\mathbf{1}$. Comparison of in vitro rumen systems}

\begin{tabular}{llccc}
\multicolumn{1}{c}{ Reference } & Type & Mixing & Permeability & pH control \\
Warner (1956) & B & - & + & - \\
Davey, Cheeseman \& Briggs (I960) & CP & - & \pm & - \\
Stewart, Warner \& Seeley (I961) & CS & + & - & - \\
Gray, Weller, Pilgrim \& Jones (1962) & BF & + & + & - \\
Rufener, Nelson \& Wolin (1963) & CP & + & - & + \\
Slyter, Nelson \& Wolin (1964) & CFP & + & + & - \\
Aafjes \& Nijhof (Ig67) & CFB & + & - & + \\
Czerkawski \& Breckenridge (1969) & B & - & - & -
\end{tabular}

$\mathrm{B}$, batch culture; $\mathrm{C}$, continuous culture; $\mathrm{P}$, periodic feeding; $\mathrm{S}$, steady-state; F, flow-through. + , featured; - , not featured.

necessary' and the apparatus was maintained at $39^{\circ}$ in a water bath. The apparatus reported by Davey, Cheeseman \& Briggs (1960) also employed a sac suspended in dialysing solution but the solution was pumped continuously and was not re-used, so that a constant rate of diffusion could be maintained. This was considered to be essential in an apparatus intended for continuous operation. $\mathrm{A} \mathrm{N}_{2}-\mathrm{CO}_{2}$ mixture was bubbled through the culture vessel, which was fitted with sampling ports and a $\mathrm{pH}$ electrode system, though no attempt was made to control $\mathrm{pH}$.

Stewart, Warner \& Seeley (I96I) constructed a steady-state system. The apparatus was a simple chemostat with a mechanical stirrer but without facilities for dialysis.

The use of a double-acting syringe in the apparatus of Gray, Weller, Pilgrim \& Jones (1962) allowed the establishment of constant culture volume, since culture material was removed from the vessel at the same rate as saliva was added. This was a semipermeable system with a reciprocating agitator which acted on a wire cage carrying the dialysis membrane. This equipment was employed for batch experiments of a few hours duration.

The impermeable system of Rufener, Nelson $\&$ Wolin $\left(19^{6} 3\right)$ was unique in its use of mixed ion-exchange resins for $\mathrm{pH}$ control. Agitation of the culture was by external rocking action and, with the culture volume kept constant by withdrawing liquor before adding fresh substrate, cultures were maintained for periods in excess of $200 \mathrm{~h}$ with no apparent fall in fermentation rates.

Long-term operation was also achieved with the apparatus of Slyter, Nelson \& Wolin (1964), which used a specially constructed fermentation vessel with magnetic stirring. This equipment represented a compromise between the steady-state (chemostat) and periodic (natural rumen) approach. An artificial saliva solution was pumped continuously into the fermentor, providing a constant dilution rate; the substrate was added periodically with a concomitant removal of liquor. This equipment had provision for dialysis.

The continuous-flow, periodic-feed apparatus of Aafjes \& Nijhof ( 1967 ) had an agitation system designed to simulate the effect of rumen motility. A nylon bag contained the substrate and was attached to a reciprocating plunger running at 5 strokes/min. This was intended to imitate the flow of rumen fluid through the plant material layer as it occurs in the natural rumen. Saliva flow was provided in response to $\mathrm{pH}$ drop and a constant volume maintained with a weir overflow. 
The apparatus of Czerkawski \& Breckenridge (1969) was an impermeable, allglass, batch-culture system intended for experiments of short duration.

As a stringent test for the artificial rumen, Gray et al. (1962) suggested that the molar proportions of the VFA should compare with those of the natural rumen, on the same diet. Table 2 lists the ranges of values observed in those systems cited in Table I where such information is available.

Table 2. Molar proportions of volatile fatty acids (VFA) in in vitro rumen systems

\begin{tabular}{|c|c|c|c|c|c|}
\hline \multirow[b]{2}{*}{ Reference } & \multirow[b]{2}{*}{ Type } & \multirow[b]{2}{*}{ Permeability } & \multicolumn{3}{|c|}{$\begin{array}{l}\text { Molar proportions } \\
\text { (mol/roo mol VFA) of: }\end{array}$} \\
\hline & & & $\begin{array}{l}\text { Acetic } \\
\text { acid }\end{array}$ & $\begin{array}{l}\text { Propionic } \\
\text { acid }\end{array}$ & $\begin{array}{c}\text { Butyric } \\
\text { acid }\end{array}$ \\
\hline Davey, Cheeseman \& Briggs (1960) & $\mathrm{CP}$ & + & $46-54$ & $19-27$ & $20-24$ \\
\hline Stewart, Warner \& Seeley ( 1961 ) & CS & - & $58-63$ & $20-24$ & $11-17$ \\
\hline Gray, Weller, Pilgrim \& Jones (1962) & $\mathrm{BF}$ & + & $66-70$ & $16-19$ & $12-15$ \\
\hline Rufener, Nelson \& Wolin (1963) & $\mathrm{CP}$ & - & $64-70$ & $17-21$ & $13-15$ \\
\hline Slyter, Nelson \& Wolin (1964) & CFP & + & $66-67$ & $19-20$ & $\mathrm{x} x-13$ \\
\hline Aafjes \& Nijhof (1967) & CFP & $\vdots-$ & $54-69$ & $21-28$ & $9-13$ \\
\hline Czerkawski \& Breckenridge (1969) & $\mathrm{B}$ & - & $64-68$ & $19-24$ & $9-12$ \\
\hline
\end{tabular}

$\mathrm{C}$, continuous culture; $\mathrm{P}$, periodic feeding; $\mathrm{S}$, steady-state; $\mathbf{B}$, batch culture; $\mathrm{F}$, flow-through. $\rightarrow$, featured; --, not featured.

There appears to be little difference between fermentation patterns in the various types of in vitro rumens. The semipermeable types show similar ranges of proportions to the impermeable systems and no distinctive pattern appears to characterize the batch-culture apparatus compared with the continuous type. Another criterion of validity might be the rate of VFA production, which is higher in the three impermeable systems (Stewart et al. I96r; Rufener et al. I963; Czerkawski \& Breckenridge, I969) at $13,3 \cdot 7^{-12}$ and $\mathrm{I}^{-1} 8 \mathrm{mmol} / 1$ per $\mathrm{h}$ respectively, than in the semipermeable system of Slyter et al. (1964) (4.4 mmol/1 per h). The rate reported by Slyter $e t$ al. was calculated without taking into account the VFA which diffused out via the dialysis system and the actual rate was probably higher than that given. The very high rate reported by Czerkawski \& Breckenridge (1969) was for a batch system with high substrate concentrations and, since the figures for continuous systems are average rather than maximum values, direct comparisons should be made with caution.

Consideration was given to the effects of permeability in in vitro rumens by Louw et al. ( 1949 ) who showed that semipermeable in vitro rumens permitted better cellulose digestion than the impermeable type. Gall \& Glaws (195I) and Huhtanen, Saunders \& Gall (r954) demonstrated that the microscopic appearance and motility of the microflora were more constant during prolonged in vitro incubation with a semipermeable system. El-Shazly, Dehority \& Johnson (1960) compared three types of system directly, using VFA production, ammonia nitrogen $\left(\mathrm{NH}_{3}-\mathrm{N}\right)$ production and cellulose digestion as criteria of microbial activity. The systems compared were all-glass, semipermeable and 'continuous-flow'. 'The continuous-flow 
apparatus did not, however, allow turnover of the actual in vitro culture but provided for the diffusion of fermentation products and fresh substrate via a dialysing membrane. The dialysing solution flowed continuously and contained a basal medium to replenish the culture substrate. El-Shazly $e$ al. ( $\mathrm{I} 960$ ) concluded that there was little to choose, at least for short-term experiments of less than $z^{\circ} \mathrm{h}$, between the systems.

Given the correct conditions, cultures of rumen micro-organisms can be maintained for long periods in vitro, so that their microbiology and biochemistry reflect, to a useful extent, the natural rumen. The principal attraction of an in vitro system is the degree of control and convenience it affords in practical research. A steady-state system should exploit these properties to the full, as the usual variables are eliminated. The high degree of selectivity imposed by such a system will tend to produce less than perfect simulation of the natural rumen, but it lends itself to detailed microbiological research since it offers a high degree of stability. For studies of a nutritional or biochemical nature the continuous-flow, periodic-feed system, with bulk substrate retention in a nylon bag, appears to provide the greatest measure of realism in simulating the rumen.

\section{A continuous, steady-state, in vitro rumen apparatus}

A continuous, steady-state, in vitro rumen apparatus has been constructed at Edinburgh in an attempt to meet all the criteria arising in the foregoing discussion. This equipment was not intended to simulate faithfully the natural rumen, but to provide a highly controlled model system for comparative studies on the rumen microflora.

The apparatus, shown diagrammatically in Fig. I, has a glass culture vessel of $400 \mathrm{ml}$ working volume with a stainless steel lid sealed by a silicone rubber gasket and fitted with ports for various services, electrodes and control elements. A magnetic stirrer is fitted below the vessel. Complete mixing of culture is essential to steady-state working, but mixing must be as gentle as possible to avoid damage to the most fragile of the rumen organisms. Iobson (1965) considered magnetic stirring to be too severe for rumen bacteria but Quinn ( 1962$)$ used a magnetic stirrer at r $20 \mathrm{rev}$. min in continuous pure culture of rumen ciliates.

Substrate delivery, antifoam addition and dialysis require accurate control, and an inexpensive means of providing this using miniature peristaltic pumps has been described (Ewart, 1973). Pumping substrate is a critical operation; continuity of flow and quality is essential. Satisfactory pumping is ensured by processing the substrate material in a double shear homogenizer (Alexander, I969) to produce a free-flowing slurry with a dry matter (DM) content adjusted to $4 \%$. Foam formation at the top of the culture results in irregular effluent removal since foam is generated as rapidly as it leaves the vessel and, to counter the considerable tendency for in vitro cultures to produce foam, a silicone antifoam agent is added at a controlled rate throughout the culture period.

Regenerated cellulose tubing is the usual dialysis membrane material used in 


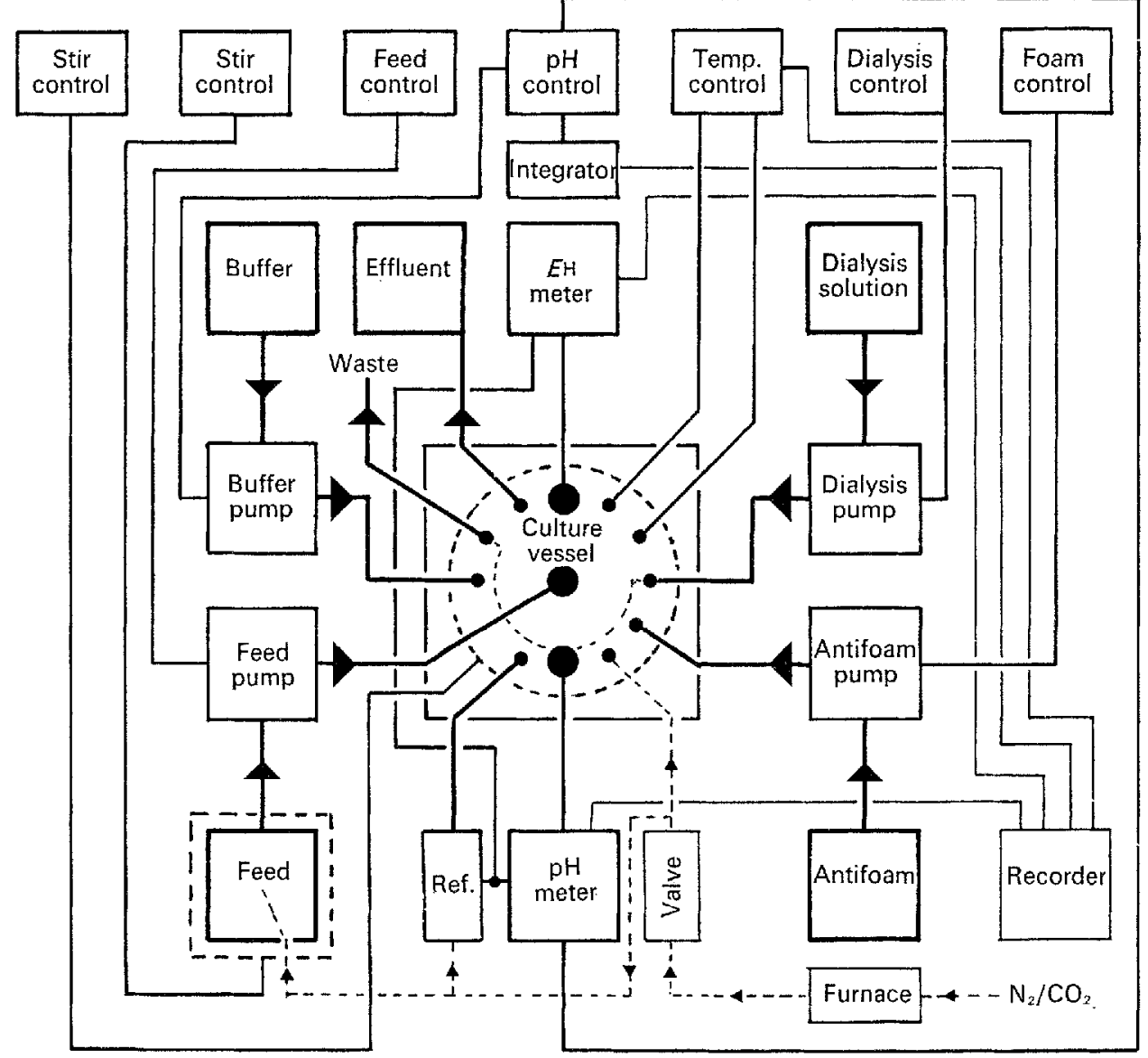

Fig. I. Diagram of continuous, steady-state, in vitro rumen system: the 'Rumenstat'.

in vitro rumens, although it is suspect in an environment of intense cellulose digestion. Renal dialysis also uses regenerated cellulose membranes but, in response to permeability problems with this material, various synthetic copolymeric membranes have been devised (Muir, Courtney, Gray \& Ritchie, I971). These membranes were found to be immune to attack by the enzymes of the rumen microflora but the technology of their production has not yet reached a stage where they can be configured and sealed in the confines of a small culture vessel. In this apparatus, tubes of regenerated cellulose foil were used and found to be reliable, probably because the ordered molecular structure of this material precluded enzymic attack. The dialysis solution, a modification of the artificial saliva described by McDougall (1948), contained concentrations of salts calculated to be isotonic with those in the in vitro culture.

The $\mathrm{pH}$ and $E_{\mathrm{H}}$ of the culture are measured by conventional means with a common reference element serving the glass $\mathrm{pH}$ electrode and the platinum $E_{\mathrm{H}}$ electrode.

The $\mathrm{pH}$-measuring circuit provides a signal for the $\mathrm{pH}$ control unit which, like all 
of the electronic circuitry, was specially built and makes use of linear integratedcircuit components. Artificial saliva, serving as the $\mathrm{pH}$ control agent, is delivered by a peristaltic pump. An integrator is connected to this control system and a recorder trace shows the rate of $\mathrm{pH}$ adjustment.

There are also control systems for the culture and feed-slurry stirrers, culture temperature and flow rate of oxygen-free gas. This gas $\left(\mathrm{N}_{2}-\mathrm{CO}_{2}\right)$, which ensures anaerobiosis by maintaining positive pressure in the apparatus, also provides additional mixing in the culture vessel and transports liquid from the vessel via the effluent weir. Pressure-balancing pipes are necessary between the source of this supply, the various reservoirs and the reference electrode-liquid junction.

It is suggested that a steady-state, in vitro rumen apparatus of this type should be described as a 'Rumenstat'.

\section{Use of Rumenstat in silage studies}

The apparatus described has been used for studying the effects of silages on the rumen microflora. The work reported here is a series of trials in which silages were subjected to the same conditions in the Rumenstat and the steady-state cultures characterized.

Table 3 describes the silages used: a control silage, a silage made using a $\mathbf{I}: 4(\mathrm{w} / \mathrm{w})$ additive mixture of acetic acid and formic acid at $5.6 \mathrm{~g} / \mathrm{kg}$ fresh grass and a silage made with an acetic acid-formaldehyde mixture $(\mathrm{I}: \mathrm{I}, \mathrm{W} / \mathrm{w})$ at $9 \mathrm{~g} / \mathrm{kg}$ fresh grass.

Table 3. Analysis of silages used in the in vitro rumen system

$\begin{array}{lcccc} & \begin{array}{c}\text { Dry matter } \\ (\mathrm{DM})\end{array} & \begin{array}{c}\text { Nitrogen } \\ \text { Silage }\end{array} & \begin{array}{c}\text { Water-soluble } \\ \text { carbohydrate }\end{array} & \\ & (\mathrm{g} / \mathrm{kg}) & (\mathrm{g} / \mathrm{kg} \mathrm{DM}) & (\mathrm{g} / \mathrm{kg} \mathrm{DM}) & \mathrm{pH} \\ \text { Control } & \mathrm{I9I} & 27 \cdot 4 & 38 & 4 \cdot \mathrm{rI} \\ \text { +Acetic acid-formic acid } & \mathbf{1 9 8} & \mathbf{2 7} \cdot 7 & 96 & 4.12 \\ \text { +Acetic acid-formaldehyde } & 208 & 26 \cdot 0 & 144 & 4 \cdot 62\end{array}$

Microbiological techniques were based on those of Hungate ( 1966$)$ and Blackburn $\&$ Hobson (I962). Three groups of micro-organisms were enumerated by viable counts in media which selected for the ability to utilize cellulose, gelatin and starch as specific substrates. $\mathrm{NH}_{3}-\mathrm{N}$ concentration was determined by microdiffusion and VFA by gas-liquid chromatography.

An inoculum of a mixture of strained rumen liquor obtained from three fistulated wether sheep maintained on a constant diet of hay and concentrates was used at the start of each in vitro trial. The steady state was reached after approximately $72 \mathrm{~h}$ operation; this agrees with the findings of Slyter et al. (rg64). Steady-state values of differential viable counts, $\mathrm{NH}_{3}-\mathrm{N}$ and VFA were obtained by calculating the mean of analytical values on 3 successive days at 96,120 and $144 \mathrm{~h}$ after inoculating the culture. As the values of $\mathrm{NH}_{3}-\mathrm{N}$ were obtained on the day of sampling they were used as a reference and if the coefficient of variation exceeded $5 \%$, further samples were taken on subsequent days. 
Samples were also taken for microbiological analysis from groups of three fistulated wether sheep on diets of the same silages, at $2 \mathrm{~h}$ post feeding, after a $\mathrm{I} 4 \mathrm{~d}$ acclimatization period.

Steady-state analytical results are given in Table 4.

Table 4. Steady-state analysis of in vitro rumen cultures maintained on supplemented silages

\begin{tabular}{|c|c|c|c|c|c|}
\hline & & silages & & & \\
\hline & $\log$ & (organisms & (ml) & & \\
\hline Silage & $\begin{array}{c}\text { Starch } \\
\text { medium* }\end{array}$ & $\begin{array}{l}\text { Gelatin } \\
\text { medium* }\end{array}$ & $\begin{array}{l}\text { Celhulose } \\
\text { medium* }\end{array}$ & $\begin{array}{l}\text { nitrogen } \\
(\mathrm{mg} / 1)\end{array}$ & $\begin{array}{c}\text { rate } \\
(\mathrm{mmol} / \mathrm{l} \text { per } \mathrm{h})\end{array}$ \\
\hline Control & $6 \cdot 63$ & $6 \cdot 5^{8}$ & 5.77 & $76 \cdot 35$ & $3 \cdot 8$ \\
\hline + Acetic acid-formic acid & $6 \cdot 33$ & $6 \cdot 29$ & 6.40 & 66.92 & 3.9 \\
\hline +Acetic acid-formaldehyde & $6 \cdot 46$ & $5 \cdot 38$ & $5 \cdot 5 \mathrm{x}$ & $28 \cdot 45$ & $3 \cdot 6$ \\
\hline
\end{tabular}

*Counting media which selected for the ability to utilize starch, gelatin or cellulose.

More organisms were counted from the control silage culture than the treated silage cultures, on the starch medium $(P<0.05)$. With the gelatin medium fewer organisms were counted in the instance of acetic acid-formaldehyde-treated silage $(P<0.05)$. Counts on cellulose medium showed significant differences $(P<0.05)$ among the three silages. These differences were also obtained with the fistulated sheep (Table 5).

Table 5. Viable counts of rumen micro-organisms in fistulated wether sheep

\begin{tabular}{|c|c|c|c|}
\hline \multirow[b]{2}{*}{ Silage } & \multicolumn{3}{|c|}{ Log (organisms/ml) } \\
\hline & $\begin{array}{c}\text { Starch } \\
\text { medium* }\end{array}$ & $\begin{array}{l}\text { Gelatin } \\
\text { medium* }\end{array}$ & $\begin{array}{l}\text { Cellulose } \\
\text { medium* }\end{array}$ \\
\hline $\begin{array}{l}\text { Control } \\
\text { + Acetic acid-formic acid } \\
\text { + Acetic acid-formaldehyde }\end{array}$ & $\begin{array}{l}6 \cdot 22 \\
5 \cdot 78 \\
6 \cdot 42\end{array}$ & $\begin{array}{l}6 \cdot 59 \\
6 \cdot 5+ \\
6 \cdot 22\end{array}$ & $\begin{array}{l}5 \cdot 14 \\
6 \cdot 57 \\
6 \cdot 37\end{array}$ \\
\hline
\end{tabular}

*Counting media which selected for the ability to utilize starch, gelatin or cellulose.

The microbiological results in vivo correlate well with those obtained in vitro in the instance of counts on gelatin and cellulose medium $(r=0.94, P<0.01$ and $r=0.85, P<0.05) . \mathrm{NH}_{3}-\mathrm{N}$ concentrations in vitro also correlate well with the counts on the gelatin medium $(r=0.94, P<0.01)$.

Total VFA production rates were similar, suggesting that this is a characteristic of the culture conditions rather than the substrate. Metabolic energy production by the rumen micro-organisms is linked to growth rate and reflected in total VFA production. At a steady state, growth rate is fixed by the culture dilution rate, which was identical in each instance.

There appears to be considerable research potential in an apparatus of this type, especially because the culture conditions can be widely but accurately varied.

In addition, the stable and definable steady-state culture is an ideal means of determining directly the effects of various substrates on the rumen fermentation. 


\section{REFERENCES}

Aafjes, J. H. \& Nijhof, J. K. (1967). Br. vet. I. 123, 436 .

Adler, J. H., Dye, J. A., Boggs, D. E. \& Williams, H. H. (1958). Cornell Vet. 48, 53.

Alexander, R. H. (1969). Lab. Pract. 18, 63.

Blackburn. T. H. \& Hobson, P. N. (1962), F. gen. Microbiol. 29, 69.

Czerkawski, J. W. \& Breckentidge, G. (1969). Br. F. Nutr. 23, 5r.

Davey, L. A., Cheeseman, G. C. \& Briggs, C. A. E. (1960). Y. agric. Sci, Camb. 55, 55.

Dawson, R. M. C., Ward, P. F. V. \& Scott, T. W. (1964). Biochem. F. 9o, 9.

El-Shazly, K., Dehority, B. A. \& Johnson, R. R. (1960). J. Dairy Sci. 43, 1445.

Ewart, J. M. (1973). Lab. Pract. 22, 575.

Gall, L. S. \& Glaws, W. L. (195I). Bact. Proc. p. 20.

Gray, F. V. (1947). F. exp. Biol. 24, I.

Gray, F. V., Weller, R. A., Pilgrim, A. F. \& Jones, G. B. (1962). Aust. F. agric. Res. r3, 343.

Harbers, L. H. \& Tillman, A. D. (I962). J. Anim. Sci. 2I, 575.

Herbert, D., Phipps, P. J. \& Tempest, D. W. (1965). Lab. Pract. 14, 1150.

Hobson, P. N. (1965), $\mathscr{\%}$. gen. Microbiol. 38, I6I.

Hobson, P. N. (1972). Proc. Nutr. Soc. 31, 135.

Huhtanen, C. N., Saunders, R. K. \& Gall, L. S. (1954). F. Dairy Sci. 37, 328.

Hungate, R. E. (1966). The Rumen and its Microbes. London: Academic Press.

Jannasch, M. W. (1965), Lab. Pract. 14, 1162.

Kiddle, P., Marshall, R. A. \& Phillipson, A. T. (195 I). 7. Physiol., Lond. 113, 207.

Louw, J. G., Williams, H. H. \& Maynard, L. A. (1949). Science, N.Y. 110, 478.

McDougall, E. I. (I948). Biochem. $\mathscr{J} .43,99$.

Masson, M. J. \& Phillipson, A. T. (I95I). 7. Physiol., Lond. 113, I89.

Monod, J. (1950). Annls Inst. Pasteur, Paris 79, 390.

Muir, W. M., Courtney, J. M., Gray, R. A. \& Ritchie, P. D. (1971). F. biomed. Mater. Res. 5 , 415.

Novick, A. \& Szilard, L. (1950). Proc. natn. Acad. Sci. U.S.A. 36, 7o8.

Parthasarathy, D. \& Phillipson, A. T. (I953). F. Physiol, Lond. I21, 207.

Postgate, J. R. (1965). Lab. Pract. 14, i 140.

Powell, E. O. (1965). Lab. Pract. 14, I 145.

Quinn, L. Y. (1962). Appl. Microbiol. 10, 580.

Rufener, W. H. Jr, Nelson, W. O. \& Wolin, M. J. (1963). Appl. Microbiol. I1, I96.

Slyter, L. L., Nelson, W. O. \& Wolin, M. J. (1964). Appl. Microbiol. 12, 374.

Stewart, D. G., Warner, R. G. \& Seeley, H. W. (I961). Appl. Microbiol. 9, I50.

Starks, D. W. (1956). Can. F. Microbiol. 2, 56.

Warner, A. C. I. (1956). F. gen. Microbiol. x4, 733 . 